\title{
SHARED SERVICES - IMPLEMENTATION AND CONTINUOUS EVOLUTION (Article 2 of 3)
}

\author{
TN van der Linde, AL Boessenkool \& CJ Jooste, University of Johannesburg
}

\begin{abstract}
Purpose: Now that an organisation understands the concept of shared services (Article 1), it needs to implement shared services as a business model. The purpose of this second article in the trilogy is to describe the phases during the implementation process, as well as the various models through which a shared services business unit will evolve to continuously add value to the organisation.
\end{abstract}

Methodology: A comprehensive literature study was conducted in order to:

- Determine the steps in implementing a shared services business model,

- Determine the various models associated with a shared services business unit,

- Determine how the continuous evolution of shared services results in moving from one shared services model to the next shared services model.

Findings: In this article, a framework is generated to help organisations understand the various phases and steps it needs to go through to successfully implement a shared services business unit. This work has further potential: when applied correctly, organisations will provide a business environment where effectiveness and efficiency is a given.

Implications: This article presents the context for organisations to implement a shared services business model and to continuously evolve from one shared services business model to the other to create value for the organisation. The findings are important for organisations that are in the process of implementing or have implemented shared services, as they can easily stagnate and fall into the trap of centralisation.

Value: This article provides an understanding of what is required for the successful implementation of shared services. This value is further enhanced through continuous evolution from a basic shared services business model to the virtual shared services business model and beyond.

Key words and phrases: Mobilise, assess, design, implement, continuous evolution, basic model, marketplace model, advanced marketplace model, independent business unit, virtual shared services.

\section{INTRODUCTION}

In the first article in the trilogy, it was indicated that shared services is tactical in nature and that shared services aims to support the organisation's strategy through the consolidation of support activities into a business unit that operates on business principles. It was also indicated that time honoured strategies such as decentralisation or centralisation without improving work processes, or technology solutions without standardised source data, will no longer work. Gunn, Carberry, Frigo and Behrens (1993:22), are of the opinion that "Shared services is a new management concept for addressing these issues". McKinlay (2006:1) is also of the opinion that an added benefit of shared services is the sharing of "best practises" across an organisation.

Shared services does not happen. It is a time consuming process loaded with obstacles, deviations and cessations. The implementation of a shared services business unit is not the end of the shared services journey, as it is but a brief stopover on the shared services journey. An organisation like Ford Europe (e-HR shared services) already takes shared services to a new dimension (Skerry, 2001: 28), with other organisations not only following, but leapfrogging shared services business models.

\section{SHARED SERVICES ROADMAP}

Figure 1 presents the roadmap that an organisation needs to follow if it wants to implement a shared services environment. Each of the four phases of: mobilisation; assessment; design; and 
implementation are briefly discussed in order to arrive at the first model of shared services, which is the basic model (Figure 2).

Figure 1: Road to shared services

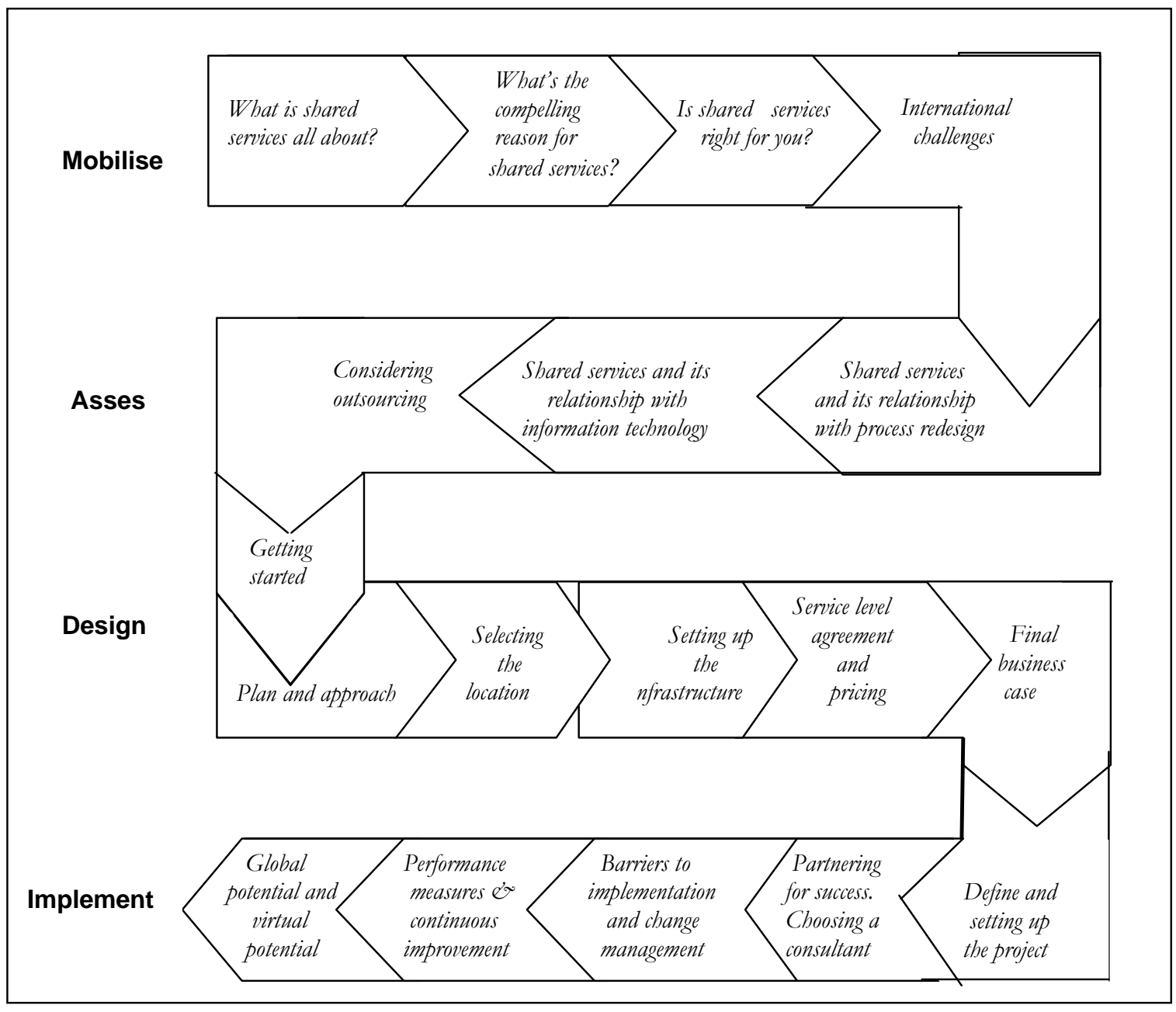

Source: adapted from Schulman, Harmer, Dunleavy and Lusk. (1999:xvii)

To realise the true value-adding potential, shared services cannot be stuck in the basic model, but will have to advance to the marketplace model, the advanced marketplace model, the independent business unit model, and ultimately global and virtual shared services. These models are introduced and discussed in the remainder of the article.

\section{Mobilisation}

This is the hard selling phase of shared services. The board of directors and senior management must be made aware of something called "shared services". This is where senior management gets educated with regards to what shared services is, what it is not, the advantages and disadvantages, as well as the alternatives. Too often, the supporting processes are seen by executives and senior managers as "non-value added" (Schulman et al., 1999:1), and as such receives little management attention. When these processes operate as free-standing businesses, they indeed add value. The commitment of senior management is of crucial importance, because without it, the process is destined for failure. This is also the opportune time for senior management to appoint one of their own to take ownership of the process, drive it, and take the full responsibility and accountability for it. 
During the mobilisation phase, the "seller" of the shared services concept must focus on:

- The concept of shared services, what it is, what it is not and the characteristics of shared services.

- The compelling reasons for an organisation to pursue shared services.

- Shared services as the correct business model for the organisation.

- Organisational and international challenges that will affect the organisation and the implementation of shared services.

\section{Assessment}

After the concept of shared services has been bought by the board, executive committee and the employees, an analysis of the current business model of the organisation is required. This is the "as is" analysis. Current business processes, procedures, people, technology and organisational requirements must be evaluated to determine whether they fit the value added goals of the organisation. Products, services and the cost of delivery must also be determined, as it will set the standard against which changes will be measured. Quinn, Cooke and Kris. (2000:10) describe the following "as is" scenarios:

- The "as is" picture - current products and services,

- The "as is" picture - current products and related service costs,

- The "as is" picture - comparison to external benchmarks,

- The "as is" picture - client satisfaction,

- Shared services and its relationship with process re-engineering and redesign,

- Shared services and its relationship with information technology,

- Building the business case to proceed.

After the "as is" analysis, a business case will now be presented to the board and senior management to gain approval for the next step of the shared services process.

\section{Design}

This is the blueprint of how the shared services business unit will operate. It lays down the structure of the shared services business unit, services that will be delivered (transactional and professional), the location of the shared services business unit, and service level agreements. According to Quinn et al. (2000:127), location can, for example, be a "green field" location - that is a new location and often in a different country - to gain further advantages like lower taxes, a flexible labour force and employees with different skills. Location can also be a "brown field" location, whereby the shared services centre is retained within the organisational current structure with the specific benefit to retain skilled and experienced manpower. This final business case is then presented to senior management for approval before the implementation.

Quinn et al. (2000:117-136) designed and developed shared services through the following points:

- Shared services as a separate entity,

- Separation of shared services from governance functions,

- Separation of transactional processing from professional and advisory services,

- Shared services reporting,

- Internal structures of shared services,

- Locating shared services centres,

- Culture and language of location,

- Leading the shared services organisation,

- Leading the transactional processing centre,

- Leading professional and advisory services.

After acceptance of this business blueprint, the organisation will move towards the final phase of establishing a shared services centre, namely implementation. 


\section{Implementation}

The shared services program and project is now being implemented. Strong program and project management is integral to success, as are strong change management skills (Schulman et al., 1999: 185). This is also the phase that the change management process is completed and staff deployed to the shared services business unit. The continuous process of evaluation, business process reengineering and benchmarking starts to take place. According to Cecil (2000:66), this process of reengineering, implementation, evaluation and benchmarking can take up to three years.

\section{SHARED SERVICES - THE JOURNEY}

After progressing through the design and implementation processes, shared services finally arrives at its identifiable shared services business model, that of the basic model. As shared services per se is "tactical" (Schulman et al., 1999:35), and in this way assists the organisation to reach its strategic goals, it needs to comply with the shared services definition (the concentration of organisational resources performing like activities, typically spread across the organisation, in order to serve multiple internal partners at a lower cost and with higher service levels, with the common goal of delighting external customers and enhancing corporate value) of continuous improvement and embark on a new journey to the succeeding (and other) models.

\section{The Basic Model}

At its most basic, the move to shared services involves the consolidation of transactional processing and administrative work. Figure 2 presents the basic model where the predominant drivers are cost reduction through economies of scale, standardisation of processes, and a focus on customer service.

\section{Figure 2: The basic shared services model}

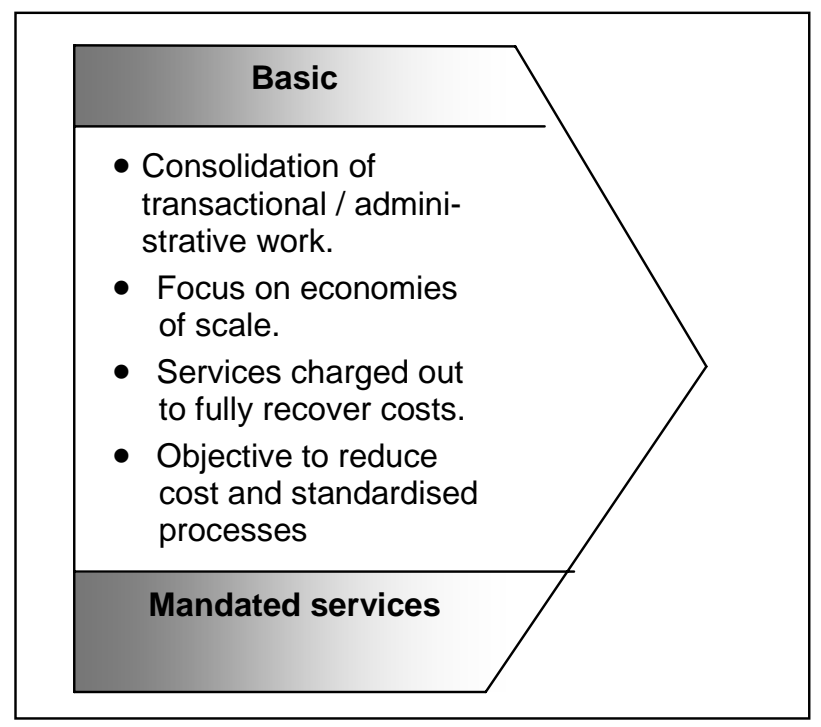

\section{Source: adapted from Quinn et al. (2000:25)}

The focus on customer service differentiates shared services from consolidation of transactional services. Shared services must start from the customer vision, asking what benefits will accrue to the customer and what levels of service will satisfy them. The basic transactional model is also a mandatory service as all business units and companies must use this service within an organisation, and are not allowed to go outside and source that particular service. An example of such a basic mandatory service is services such as payroll and accounts payable. 
Moving to a basic model creates value at two levels. Firstly, operating costs are lower with a positive effect on the bottom line. Secondly, corporate functions and business units reduce human resources at a transactional level, which can be re-positioned at a tactical and strategic level (Quinn et al., 2000:27).

\section{The Marketplace Model}

The next step in the shared services journey is an evolution to the marketplace model. These services are voluntary in that clients will have a choice regarding whether or not to use them. The difference between the marketplace model and the basic model is the inclusion of professional and advisory services, as well as the separation of governance related activities. The professional and advisory services operate on a principle of an internal consulting service. Figure 3 graphically depicts the marketplace model in the shared services journey.

\section{Figure 3: Shared services - the marketplace model}

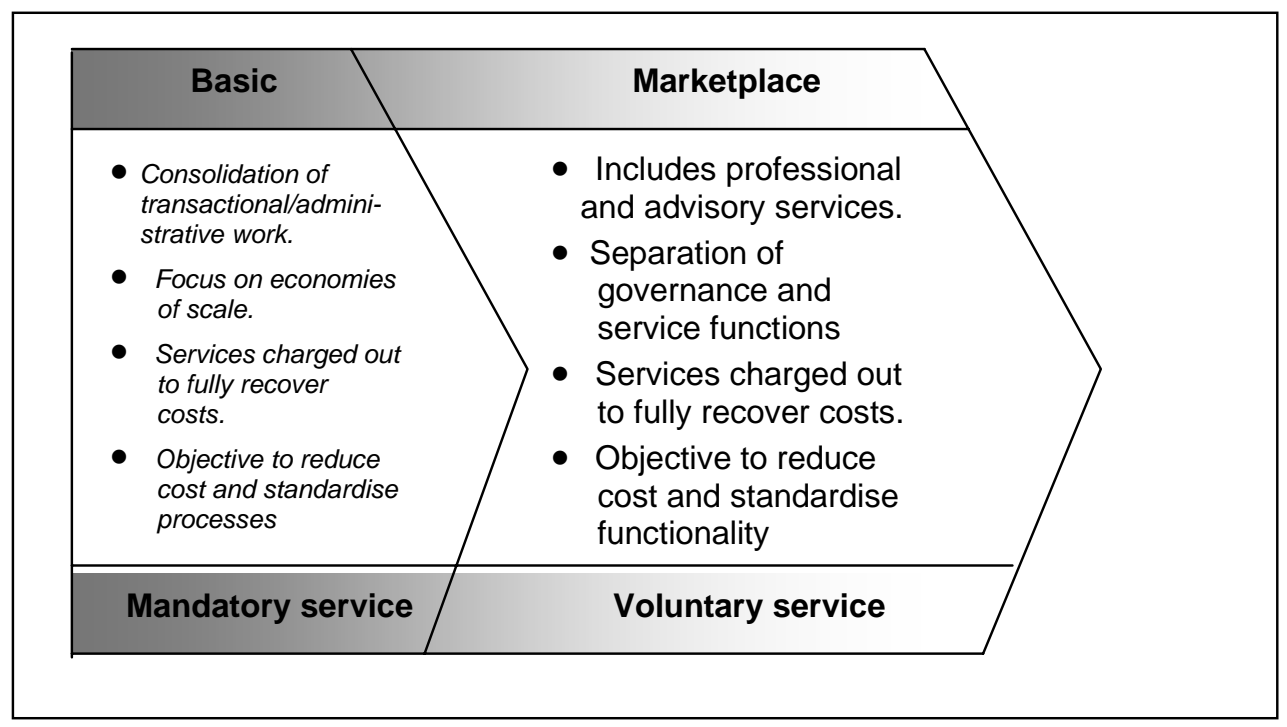

Source: adapted from Quinn et al. (2000:28)

According to Quinn et al. (2000:29), the separation of governance activities from the delivery of services is "the move to a real internal marketplace". The separation of governance activities from service delivery can be explained by the following example: Organisational policy lays down that cellular phone expenses in excess of R500.00 will be reimbursed only for business related calls. On scrutinising a reimbursement claim of $\mathrm{R} 700.00$, the claims clerk notices that all the excess of R200.00 was claimed for private calls. The clerk highlights the private calls and sends the claim back to the claimant. In this example, the claims clerk is performing a service while enforcing a policy. In a shared services environment, the clerk receives the claim, sees the approved line manager signature, and consequently processes the claim. Quinn et al. (2000:30) state that "In shared services, the clerk is not required to enforce policy". In shared services, it works best when the people who deliver the service are separated from those who develop, administer and ensure compliance with corporate policy and standards.

\section{Shared Services - The Advanced Marketplace Model}

The advanced marketplace model (Figure 4) takes the total service approach further by bundling functional competencies (human resources, finance, information technology) with cross-functional synergies (people, knowledge, systems) to create a total service solution. This total service solution also implies that the shared services business unit is not protected any more and the internal customer can purchase the service from outside. In the advanced marketplace model, pricing is 
based on market prices. The shared services business unit must compete for the internal customers' business not only on pricing, but also on offering, efficiency and effectiveness. In the basic and marketplace models, the shared services business unit is protected from outside competitors as business units are prohibited from using outside service providers for a period of up to two years. This serves to enable the business unit time to establish itself (Van Denburgh \& Cagna, 2000:5). During this period, senior management can establish whether the shared services business unit supports the overall business strategy, or whether it should be outsourced.

Figure 4: Shared services - the advanced marketplace model

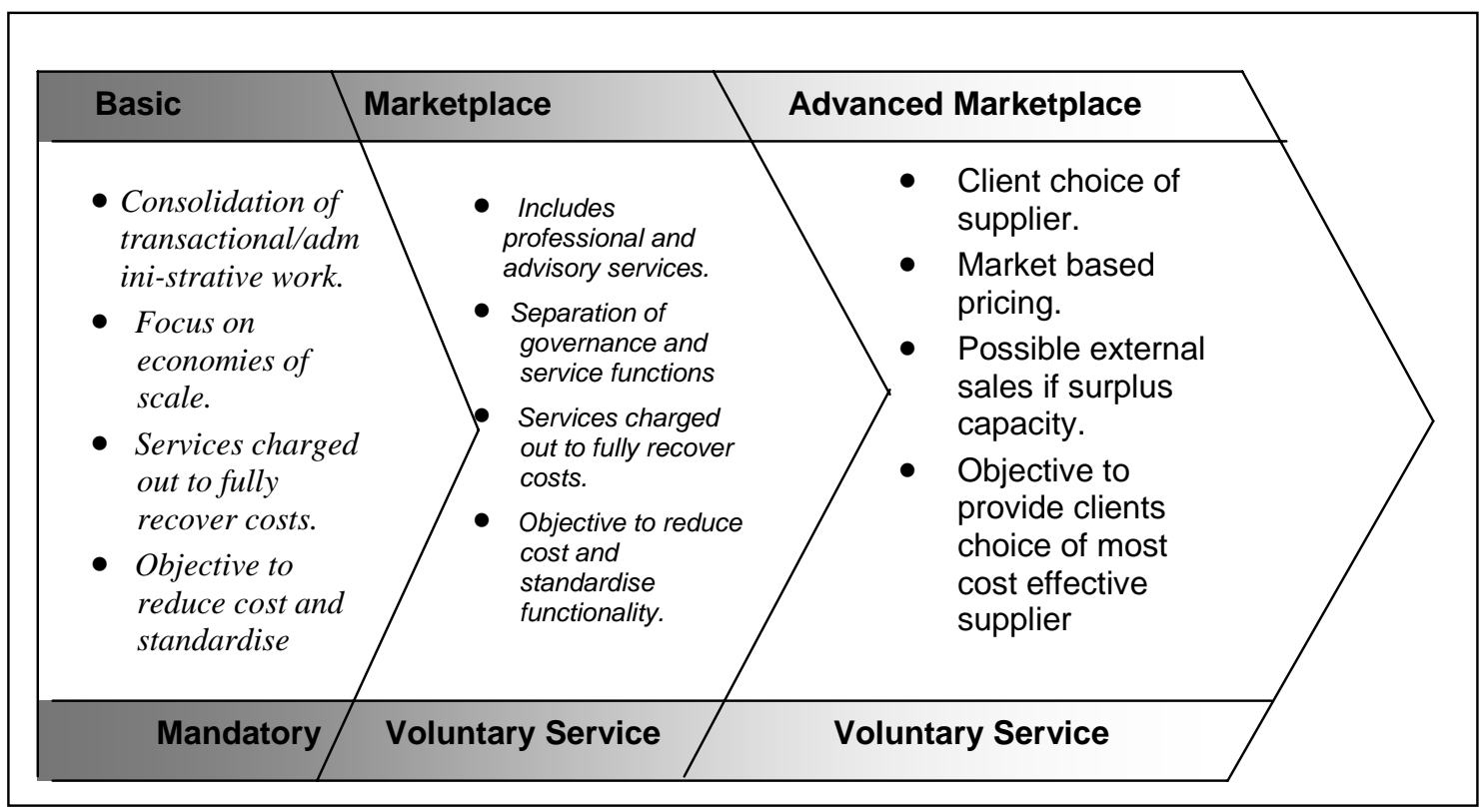

Source: adapted from Quinn et al. (2000:34)

In the advanced marketplace model, the shared services product offering can respond to changing market and customer needs quickly and efficiently, due to flexibility. In addition, the shared services moves into the realm of supporting the organisation's vision by being the supplier of choice, and by supporting cross-functional strategies. Performance measures should focus on achieving the organisation's vision, market-based pricing and possible external sales of the function and related activities.

\section{Shared Services - The Independent Business Model}

In this model, the idea for shared services is to operate as a separate business entity where profits are retained. It does not only have internal customers as clients, but also serves multiple organisations. In the shared services journey, and according to Quinn et al. (2000:23-37), the final step in the journey is as presented in Figure 5, where the shared services business unit is a separate business entity, profits are retained, it serves multiple organisations, and its aim is to generate profits. 
Figure 5: Independent business unit model

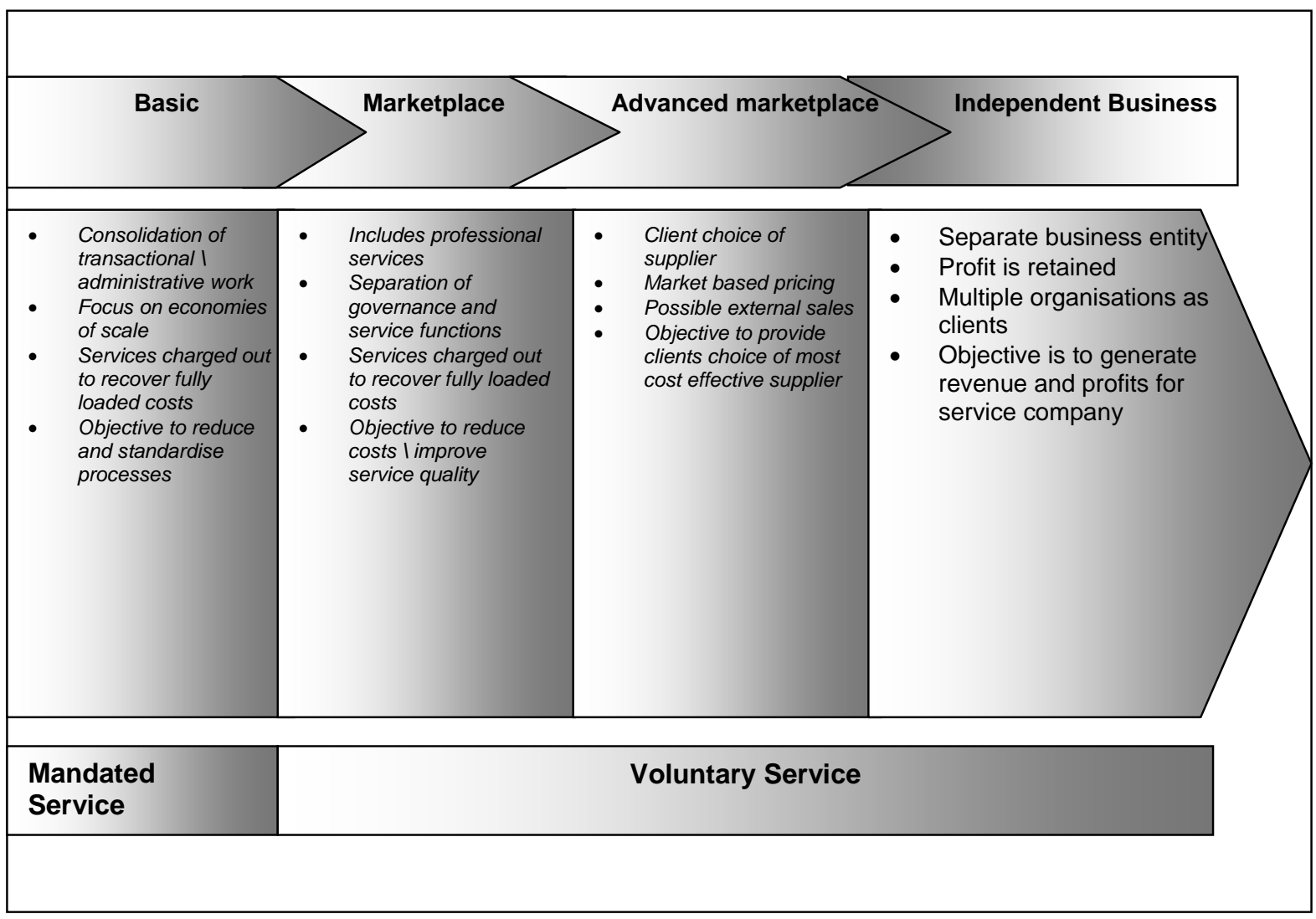

Source: adapted from Quinn et al., (2000:24)

Few shared service business units are in the ambit of independent business units. According to Gunn Partners (2001:18), only $17 \%$ of today's shared services are separate legal entities. They are also of the opinion that "commercialising" the shared services business unit will lead to a higher performance of the shared services business unit (Gunn Partners, 2001:19).

\section{Shared Services - The End of the Journey?}

Is reaching the stage of the independent business unit indeed the end of the journey? Proponents of shared services will most definitely argue that the answer must be "no". Thoughts have already been expressed that the next step in the journey is the establishment of a "virtual" shared services business unit. According to Bangemann (2001:15-18), virtual shared services is the next step. To successfully transform a shared services organisation to a virtual organisation depends on the recognition that a virtual shared services organisation "is a working network based on well-designed processes and an advanced IT platform; it is also a personnel network based on trust, fairness, cooperation and competence". The skill requirement for a virtual shared services organisation (SSO) is higher than in any other shared services organisation (Bangemann, 2001:17). This further development in shared services is graphically presented in Figure 6, where the shared services development is projected over organisational maturity ( $\mathrm{X}$ axis) and efficiency ( $\mathrm{Y}$ axis). As the shared services matures, it will move to a higher order shared services organisation with a corresponding increase in efficiency. Dupont's Titus (Forst, 2001:5) states further development as: "By e-enabling delivery of our offerings, we can significantly improve productivity, increase customer satisfaction via self-service, free knowledge workers for more value-adding tasks, and increase both flexibility and speed of delivery".

Figure 6: Future Development Of Shared Services 


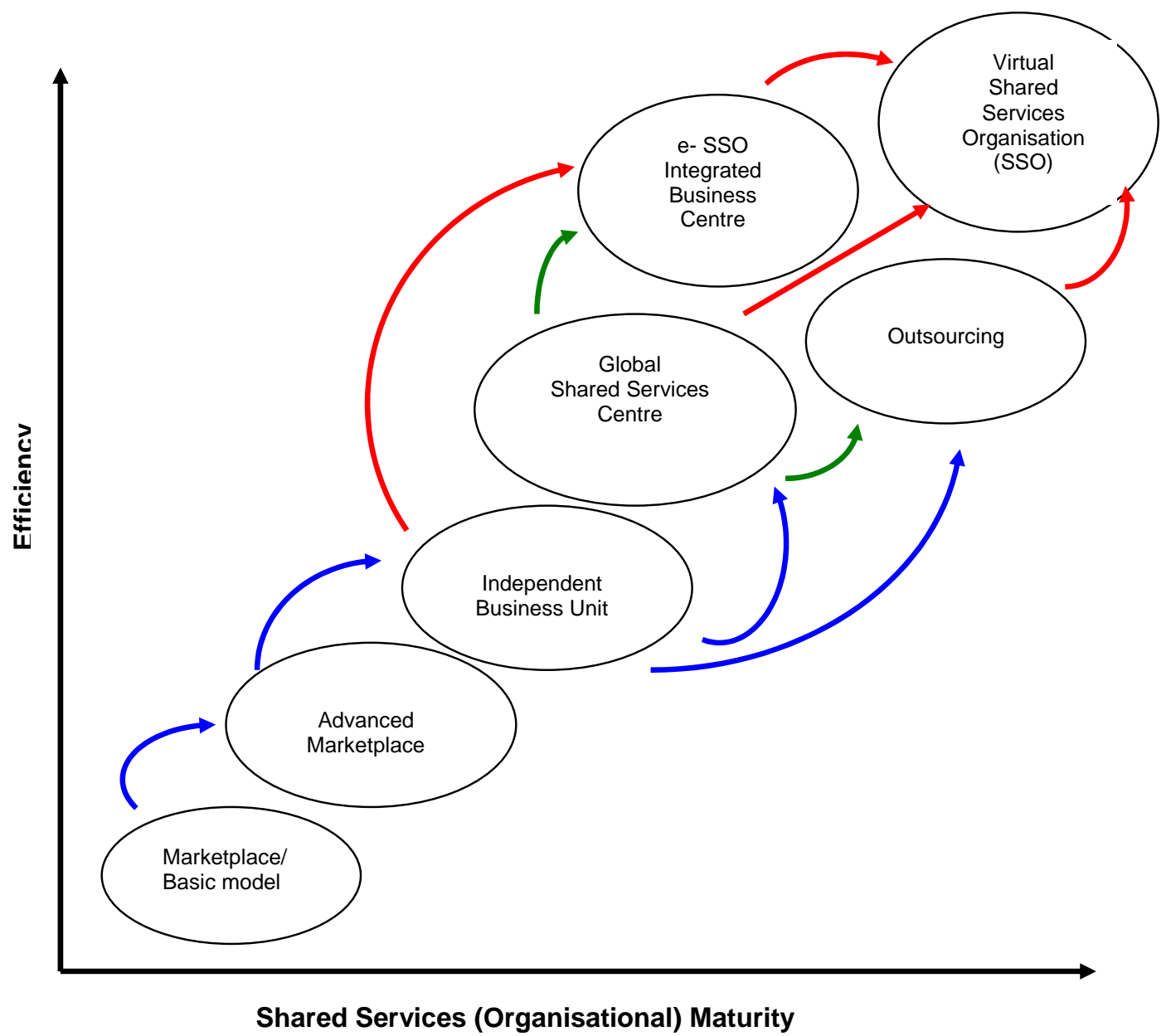

Source: adapted from Bangemann (2001:17)

A word of caution must however be expressed: e-enabling of shared services is not equal to virtual shared services, but will assist in the evolution into a virtual shared services model. According to Hedberg, Dahlgren, Hanson and Olve (2000:22), a virtual organisation (also known as an imaginary organisation $-\mathrm{IO}$ ) will be built on:

- Value creation with and for customers,

- A clear and attractive vision,

- Leadership and empowerment,

- Shared values, and

- Information technology (which includes e-enabled business).

$\bullet$

From the above discussion, it can be seen that shared services through its evolution does comply with the above building blocks and can be a true virtual organisation (imaginary organisation).

\section{MANAGERIAL RECOMMENDATIONS}

Shared services started off as a management concept to achieve benefits that go beyond cost savings. This management concept of shared services can be compared to a journey, and to comply with a basic element of the shared services definition of "continuous improvement", indicates a continuous journey. To assist the organisation in managing this journey, certain identifiable 
milestones have to be reached to serve as a reference point before continuing on this "continuous improvement" journey. It is recommended that management must:

- Mobilise and assess resources to:

o Understand shared services,

o Determine if the organisation can transform people, business processes and technology,

o Determine if there is a case for a shared services business model

- Design the shared services business model and present the final business case.

- Implement the shared services business model by starting with the basic model. Only once the indicators (characteristics) of this model have been reached can the shared services business unit evolve to the next model.

- Know in which model of shared services the shared services business operates, as it will influence the transformation and planning of the shared services business unit.

- Take note that the shared services can be in a prior shared services business model with certain activities and in an advanced shared services business model with other activities.

- If a shared services business unit and/or activity stays in a specific shared services business model for longer than a two year period, it is indicative of stagnation and that the service offering of the shared service does not continuously improve. As such, the shared services might become a target for "outsourcing".

The shared services journey through its various models will assist the shared services business unit to become a "profit centre" instead of staying a "cost centre."

\section{CONCLUSION}

The first article in the trilogy introduced the concept of shared services. This second article presents the framework for the implementation of a shared services business model. The hardest part is to assess the current internal business environment of the organisation in determining if it is ready for a shared services business model and making a business case for such a transformation. After the business case has been accepted, the designed shared services business model can be implemented.

In the basic model, the shared services are characterised by the consolidation of transactional and administrative work, a focus on economies of scale, the full recovery of costs, and the standardisation of business processes. Once these characteristics have been established, the shared services business unit needs to evolve to the market place model of shared services. In this model, professional services are added to the service offering and the separation of the governance function and service function occurs. In the advanced marketplace shared services model, the service offering from the shared services business unit is so good that the shared services becomes the supplier of choice. The pricing of the service product is market-related and surplus capacity exists that can be used to generate external sales. Once external sales can be realised, the shared services business unit can move into the independent business unit shared services business model. In the independent business unit model, the shared services become a separate business entity, profits are retained, and the shared services business unit serves multiple organisations (not only the parent organisation).

This stage does not however signify the end of the journey, as shared services have already evolved into the realm of virtual shared services. Virtual shared service is not the e-enabling of shared services, but rather a personnel network based on trust, fairness, cooperation and competence. The skills required in a virtual shared services model are higher than in any other shared services business model. 
Now that once the shared services business model is operational (and institutionalised), it needs to be managed. The third and final article in this trilogy of articles will address the key success factors required for the management of a shared services business unit.

\section{REFERENCES}

Bangemann T. 2001. Will the future of shared services be virtual? Shared Services News, 3(6) September.

Cecil R. 2000. Shared services moving beyond success. Strategic Finance, April [Online] Available from: http://infotrac.london.galegroup.com/itweb/rau

Forst LI. 2001. Shared services grow up. Journal of Business Strategy, 22(4) July/August [Online] Available from: EBSCOHost: Business Source Premier: http://search.global.epnet.com

Gunn RW, Carberry DP, Frigo R \& Behrens S. (1993). Shared services: major companies are reengineering their accounting functions. Management Accounting (USA). November v75 n5, [On-line] Internet: http://www.infotrac.london.galegroup/itweb/rau

Gunn Partners. 2001. Commercialising Shared Services. A compelling idea... a long way from reality. Paper presented at the shared services for the HR function conference. $24^{\text {th }}-25^{\text {th }}$ September 2001. One Whitehall Place. London.

Hedberg B, Dahlgren G, Hanson J \& Olve NG. 2000. Virtual organisations and beyond: Discovering imaginary systems. Chichester: John Wiley and Sons, Ltd.

McKinlay J. 2006. Why shared services will benefit everyone. Computer weekly, August 25 [Online] Available from: EBSCOHost: Business Source Premier: http://search.global.epnet.com

Quinn B, Cooke R \& Kris A. 2000. Shared services: mining for corporate gold. London: Pearson Education Limited (Financial Times - Prentice Hall)

Schulman DS, Harmer MJ, Dunleavy JR \& Lusk JS. 1999. Shared services: adding value to business units. New York: John Wiley \& Sons, Inc.

Skerry J. 2001. Access the capabilities of new technologies to adopt the e-HR shared services business model. Ford Europe. Paper presented at the shared services for the HR function conference. $24^{\text {th }}-25^{\text {th }}$ September 2001. One Whitehall Place. London.

Van Denburg E \& Cagna D. 2000. Doing more with less. Electric Perspectives, January/February 25 (1) [Online] Available from: EBSCOHost: Business Source Premier: http://search.global.epnet.com 